\title{
A SWOT Analysis of the Contribution of Community Support Frameworks to Tourism: The Case of Syros Island
}

\author{
Panayiota Dionysopoulou \\ Hellenic Open University, 11 Fornezi str., Athens, 17675, Greece \\ yoldi@minedu.gov.gr \\ John Mylonakis \\ 10 Nikiforou str., Glyfada, Athens, 16675, Greece \\ imylon@otenet.gr \\ Christina Mendrinou \\ 138 Ag. Dimitriou, Peiraias, 18544, Greece \\ cmendrinou@yahoo.gr
}

\begin{abstract}
Tourism is the main sector in Greece contributing the most to the economic and social growth. It accounts for more than $10 \%$ of the gross national product with significant for the economy and the society trends. Tourism has gained considerable comparative advantage as main international tourism destination place. The scope of this study is to examine the extent to which the implementation of the the Third Community Support Framework contributed to tourism development, focusing on the island of Syros (capital of the prefecture of Cyclades islands). The survey was based on structural questionnaire distributed to 200 recipients, out of which 100 questionnaires were mailed to investors and 100 to various entities, local banks and tourism offices. Research showed that it is difficult to make a positive or negative evaluation of the Community Support Frameworks. The majority of individuals and entities involved in research carried out stated that the projects funded were not adequate enough to increase the tourism development of Syros.
\end{abstract}

Keywords: SWOT Analysis; Tourism Destination; Community Support Framework; Development Programs

\section{INTRODUCTION}

Tourism is currently one of the most important sectors of the Greek economy contributing significantly to employment and investment. At the same time, the country has considerable comparative advantage as main tourism destination place [1]. Over the last decades, Greece has received large financial assistance from European Union (E.U.) Funds in the form of Community Support Frameworks (CSF). Greece spent the greater part of the E.U. financial aid from the first three Support Frameworks in the construction of tourism infrastructure sector. Nowadays, particular attention is being given to the country's competitiveness [2].

This paper attempts to explore the extent to which the 3rd Community Support Framework contributed to the implementation of tourism intervention actions, taking as example the island of Syros. Syros is the capital of the Prefecture of the Cyclades in the region of the South Aegean. In the past, the industrial era is the Neorion shipyard suffered tremendous depression 
with no prospects of comeback. Thus, the island was transformed from an industrial place to a tourism destination place. Today, people are directly or indirectly engaged in tourism, having comparatively better access to information about grants and programs compared to the other smaller islands of the Cyclades.

Despite the positive steps that have been taken in the island's tourism sector, the aim of this paper is to examine whether the 3rd CSF was fully exploited for both private and public sector. The choice of the 3rd CSF as a point of reference is not accidental if one takes into account the expertise in management gained after the realization of the two previous programs.

\section{RESEARCH METHODOLOGY}

The first reports on tourism policy appeared in the 70s. As mentioned by Hall [3], while the importance of tourism to the economy of each country dominates, there are rarely reports found referring to tourism policy. It is remarkable that even today, there is a lack in tourism policy research literature [4] compared to the huge one in other social sciences sectors. Therefore, it is not surprising the fact that recent or past literature research in evaluating E.U. Support Frameworks in Tourism in Greece is not found.

The main reasons for which research, regarding the political dimensions of tourism, has not received the proper attention in the literature [5] are:

- The reluctance of tourism policy operators to understand and accept the political nature of tourism.

- Lack of official interest in research in the tourism policy.

- Tourism was not acknowledged for many years as a serious research area.

$\circ$ The problems existing in the methodology of policy studies and administration.

The aim of this research is to explore the profile of the investors and businessmen in Syros Island that exploited the 3rd Community Support Framework. At the same time, it aims to determine whether they believe that the implementation of the $3^{\text {rd }}$ Framework helped the tourism development of Syros and to what extent. We considered as representative sample for evaluating the impact of the 3rd CSF investors on the island of Syros businessmen who either created new businesses or upgraded existing ones, as well as, entities (local authorities, banks, etc) that handled these programs.

\section{Sample selection}

The sample consists of investors and entities engaged in tourism activities in the entire island of Syros that participated in the 3rd CSF. It was also examined the Intermediate Body of the 3rd CSF and the Greek Development Company (EL.AN.ET.) located in Athens.

The survey was based on structural questionnaire distributed to 200 recipients. Specifically, 100 questionnaires were mailed to investors and 100 to various entities, such as consulting companies, the Chamber of Commerce of Cyclades, local banks' branches, the Region of the South Aegean, the Intermediate Managing Authority, the local office of the National Tourism Organization and the Municipalities.

\section{The questionnaire for investors}

The questionnaire was sent to investors by email, fax or post. Its structure of closed and open questions [6] was divided into two parts. The first part included questions concerning the respondents' profile (gender, age, type of business, operating time). The second part examined 
their views, regarding the degree of participation in the 3rd CSF, as well as, whether the 3rd CSF helped actually the tourism development of Syros.

\section{The questionnaire for entities}

This questionnaire was also structured using closed and open questions divided in two parts. The first part included questions related to age, sex, the respondents' working field and relationship with the CSF. The second part examined their views on the 3rd CSF and the degree to which this helped the tourism development of Syros. The postal, telephone and electronic contact methods [7] with respondents were successful, having no reply rejections.

\section{SWOT ANALYSIS - DESCRIPTION OF OPERATIONAL PROGRAMS}

The $3^{\text {rd }}$ Community Support Framework [8] was divided into 24 Operational Programmes, 11 of which were national sectoral policies and 13 integrated regional development programs, one for each region of Greece. The selected priorities included sectors like Human Resources, Competitiveness, Country side and Fisheries Development, Information Society, Life Quality and Regional Development (CSF 2000-2006).

The SWOT analysis presents the overall tourism situation, recording its Strengths, Weaknesses, Opportunities and Threats [9].This paper describes the special features of Syros, namely the factors that affect both the internal environment and the external environment, like growth outlook, opportunities and risks (Table 1).

Table 1. SWOT Analysis

\begin{tabular}{|c|c|}
\hline Strengths & Weaknesses \\
\hline 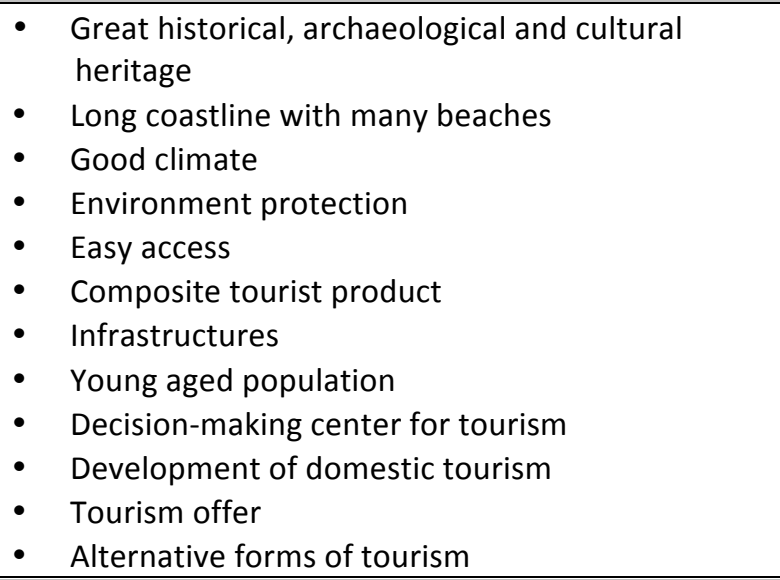 & $\begin{array}{l}\text { - } \quad \text { Low level of services offered } \\
\text { - Inadequate maintenance of archaeological sites } \\
\text { - } \quad \text { Lack of coordinated exposure - advertising } \\
\text { - } \quad \text { Low - staffing and lack of skilled staff } \\
\text { - Inadequate statistics records } \\
\text { - Improper utilization of infrastructure } \\
\text { - } \quad \text { Short-term tourist season } \\
\text { - } \quad \text { Reduced demand from foreigners } \\
\text { - Improper development of alternative forms of } \\
\text { - } \quad \text { tourism } \\
\text { - Tack of a single tourism operator }\end{array}$ \\
\hline Opportunities & Threats \\
\hline $\begin{array}{l}\text { - Increased demand for alternative forms of } \\
\text { - } \text { tourism } \\
\text { - Exilization of location } \\
\text { - } \text { framework for tourism development } \\
\text { - } \quad \text { Coastal links with large islands of Greece } \\
\text { - Ability to make interventions in the organization } \\
\text { - } \text { of the Public Administration } \\
\text { - Promotism demand increase from the foreigners } \\
\text { - And the archaeological sites } \\
\text { - Implication of new technologies } \\
\text { the 3rd CSF }\end{array}$ & $\begin{array}{l}\text { - } \quad \text { Tourism development of other islands } \\
\text { - } \quad \text { Lack of tourist packages } \\
\text { - } \quad \text { Environmental pressures from tourism development } \\
\text { - Lack of cooperation between entities } \\
\text { Lack of financial resources }\end{array}$ \\
\hline
\end{tabular}




\section{STRENGTHS}

\section{Great historical, archaeological and cultural heritage}

The comparative advantage of Syros over the other Cyclades islands is its great historical, archaeological and cultural heritage features. Its heritage is part of the tourism product and local characteristics. The combination of its natural beauties, the numerous wonderful beaches, the magnificent neoclassical buildings, the long history, the cultural events, the hospitable inhabitants, the night life, the unique culture of the island may satisfy interests of different target groups.

\section{Long coastline with many beaches}

Syros has many kilometers coastline where tourists can discover many and different style beaches. Most of them hold "Blue Flag" and are well organized. At the same time, some of them, located on the north side of the island, are promoted as "pristine". Many of them can be approached only through sea roots.

Simultaneously, according to a research made on behalf of the Cyclades Chamber, remote beaches are the main reason of attractiveness for many tourists. Coastline places could be further developed through more intense utilization of all beaches or by providing more and better services without losing their family features and protecting environmental balance.

\section{Good climate}

The island's climate is ideal for vacation 12 months a year. The long periods of sunshine and the low rainfall periods allows to develop many forms of tourism besides the model "sun and sea".

\section{Environment protection}

Syros has already received many distinctions for environmental protection, particularly for its recycling projects. Thus, apart from visitors' positive feedback ratings, this advantage can be used by the local authorities in order to attract environment-related tourists.

\section{Easy access}

Syros is connected to Piraeus port by speedboat or by ferry. The time consumed is hardly 2.5 hours by speedboat or 4 hours by ferry. It has a tiny airport and link to the rest of the Cyclades and the Dodecanese. Due to the short distance, ticket prices are quite affordable. During winter, the connection to Piraeus is realized twice a day, while during summer the daily scheduled routes are increased to four.

\section{Composite tourist product}

The tourist product of Syros is complex and includes many sub-products and services. Among these, alternative forms of tourism (sea tourism, walking tourism, cultural tourism, etc.), cultural events and casino facilities have been developed. All the above enhance the prospects of attracting new visitors. Moreover, Syros is the only island in Greece where the neoclassic Ermoupolis city, capital of Syros Island, is combined harmoniously with the medieval Ano Syros city and the traditional island village style.

\section{Infrastructures}

The island has several infrastructures, which are being developed and well preserved the last years. Taking advantage of the fact that the island is the capital of the Prefecture of Cyclades, as well as, the registered seat of the region of South Aegean, the implemented projects are many and significant. It has all basic infrastructures needed for tourism development, which give the 
possibility for further development of alternative forms of tourism, other than those already developed.

\section{Young aged population}

The fact that the majority of the population age range between 25-55 years old gives advantage to the island for future development. This age dispersion allows young entrepreneurs to invest in the island setting up new businesses and to apply new technologies.

\section{Decision-making center for tourism}

The island offers a wide range of tourism stakeholders and decision-making entities for tourism. It is the registered seat of the Chamber of Cyclades and the Development Company of Cyclades, which are entities involved in tourism development as intermediaries in development programs. Furthermore, they organize youth conferences and other educational events for tourist operators and they intervene in Central Management making suggestions in vitally tourist problems.

\section{Development of domestic tourism}

The majority of tourist visitors to the island are Greek. This gives the island the advantage of repeat visits by tourists, as well as, the possibility of extending the tourist season over summer holidays, such as Easter and Christmas. At the same time, the short distance from Piraeus and the good ferry connection is rendering the island a nice choice for weekend escapes.

\section{Tourism offer}

The tourism offer of the island is intense. Most tourism businesses are family ones. It has infrastructures that can be used for further development of alternative forms of tourism, like sports tourism and covers most needs of tourists.

\section{Alternative forms of tourism}

As aforementioned, in Syros many special and alternative forms of tourism are developed, such as cultural, conference, sports and ecotourism. All these forms are offering a great rate on total tourism demand of Syros, with high expectations for further development.

\section{Low level of services offered}

\section{WEAKNESSES}

Most entrepreneurs have other main profession. This can be justified if one takes into account the fact that Syros at first developed its industry and afterwards its tourism sector. In practice, this means that the offered services are low as many small family businessmen are not educated in providing high level services.

\section{Inadequate maintenance of archaeological sites}

Until today no any significant progress is made in preserving archaeological sites. Infrastructure is still inadequate, since no substantial interventions have taken place apart from some road signs indicating the existence of archaeological sites.

\section{Lack of coordinated exposure - advertising}

Syros does not have coordinated and continuous advertising programs due to the large number of small entities operating on the island. Each one of them promotes individually Syros as tourists' destination. In quite unorganized way many businesses participates in exhibitions, often by using old flyers or by creating their own websites. This results to excessive 
expenditure for promotion and advertising of Syros with doubtable possibility of achieving positive results.

\section{Low - staffing and lack of skilled staff}

In tourism sector, many businesses use unqualified and/or low skilled personnel. On the one hand, entities dealing with tourism are covering managerial positions with people who lack the basic tourism education. A good example is the case of the Hellenic Tourist Organization (EOT) in Syros where the local understaffed office assumes to satisfy the needs of the entire Prefecture. Under these circumstances, any kind of state controls on tourism activities is rare. It is worth mentioning the fact that a simple case of processing for the renewal of a rooms license may take quite long. Additionally, most of these family businesses operate only during the summer months. Therefore, staff is consisted of either family members, who are helping the family business, or by staff without any specialization and tourism education.

\section{Inadequate statistics records}

According to aforementioned elements, such as the existence of many entities and the understaffing of local state offices services, the reliable recording of tourism statistics is prohibited. This results to unreliable conclusions.

\section{Improper utilization of infrastructure}

On the island, there are many infrastructures which are not advertised and promoted. For example, there is the swimming pool built to Olympic specifications but has not yet been used (organization of any sport events).

\section{Short-term tourist season}

The heavy tourism season is mainly the summer months. Little tourist traffic also appears during the festive season of Easter but it lasts for few days. The use of alternative forms of tourism could increase the duration of the tourism season and particularly the development of those forms that could take place other months besides summer, like conference tourism.

\section{Reduced demand from foreigners}

Greeks are the major part of tourists visiting Syros. Foreigners hold a small proportion but slowly tending to increase. This is due to the lack of integrated tourist packages for the island. A small number of the existing packages concerns specific hotels. Meanwhile, the unorganized tourism promotion in foreign markets, from which the island has share even to new markets, will result in the continuation of this phenomenon for the next years.

\section{Improper development of alternative forms of tourism}

Alternative forms of tourism are not developed correctly and functionally while all efforts made for their development were incomplete. The main reason is the lack of good collaboration between the entities of Syros. The effort made to approach the island cruise ships is a good example. Due to entities' bad collaboration, the Commercial Association of Syros was not informed and all local shops during the first visit of these tourists were all closed.

\section{Lack of a single tourism operator}

Most of the aforementioned problems derive from the lack of a single tourism operator. An entity responsible for the local tourism development and problems solving management should be established consisting of staff specialized in tourism sectors. This entity would make decisions on all local matters related to tourism and could function as a link between the many associations and the various small businesses that exist on the island. 


\section{Traffic problems}

The intense urbanization of the center of the island, the lack of traffic lights and the lack of major arterial road are causing huge traffic problem, especially in the summer months. The matching of two vehicles per inhabitant, the existence of one main road leading to the city center and crossing the harbor (despite all unrealized decisions made to fix the problem) led the island to a traffic jungle.

\section{OPPORTUNITIES}

\section{Increased demand for alternative forms of tourism}

Syros should exploit the fact that more tourists seek alternative ways to spend their holidays. This trend is rising and is a great opportunity for the island to increase its tourist offers and overnight stays. In the island, many alternative forms of tourism can be developed due to its infrastructures that can foster growth.

\section{Utilization of location}

The geographical position of Syros in the center of Cyclades enhances the easy access from the port of Piraeus and Rafina, but also from the other islands. This position gives tourists the possibility of daily visits to other islands from Syros to Tinos, Mykonos, Paros and Naxos. This perspective should be used and promoted as an advantage for the island.

\section{Existence of an appropriate institutional framework for tourism development}

In 2009, the Special Framework for Tourism was approved including provisions protecting the environment of islands and creates the proper circumstances for the development of tourism. Moreover, in this Framework the island of Syros was mentioned as Sea Tourism Center.

\section{Sea tourism development}

The approval of the framework for tourism gives more incentives for the development of sea tourism on the island in an organized way without aggravating the environment, rural and urban.

\section{Coastal link with large islands of Greece}

The existence of coastal link with large islands, such as Rhodes and Chios, enables the growth of tourism demand from these islands. At the same time, a request should be made to the Ministry of Shipping and Aegean for connecting the island with Thessaloniki and Crete, link that existed before and now is ceased.

\section{Ability to make interventions in the organization of the Public Administration}

Syros is the registered seat of the region of South Aegean, the capital of the Prefecture of Cyclades and in parallel the registered seat of various entities, which can intervene in the organization of the Public Administration. This intervention would enable the proper and functional organization of the Public Administration, aiming at serving long-standing demands of tourism operators, as well as, those who wish to start up a business on the island.

\section{Tourism demand increase from foreigner tourists}

Syros is registered as a domestic tourism destination. The lack of integrated tourist packages, the non-rational presentation of the island in foreign tourist markets and the lack of other movements towards the increase of tourism demand from the foreigners place the visitation rates of foreign tourists very low. If all the aforementioned problems of the island were solved then tourism demand would be enhanced and the tourist season would be lengthened. 


\section{Promotion and protection of the cultural heritage and archaeological sites}

The promotion and protection of cultural heritage and archaeological sites that exist in the island would offer a new comparative advantage over competing destinations in the Cyclades. At the same time, visitors most interested in history and culture would be increased.

\section{Application of new technologies}

Nowadays, the majority of reservations and tourism promotion is realized through electronic means. The modern tourist is informed and planning its vacation from their home computer. The lack of electronic presentation of many tourism businesses, as well as, the lack of an integrated electronic presentation of the island reduces the chances of increasing tourist demand.

\section{Improvements in tourist infrastructures through the $3^{\text {rd }}$ CSF}

The application of the $3^{\text {rd }}$ CSF provides the possibility to the island to improve its tourism infrastructures, both in private and in the public sector. Its full utilization is considered to be one-way choice, not only for new projects, but also for older that require rehabilitation and modernization.

\section{Tourism development of other islands}

\section{THREATS}

The other islands of the Cyclades have tourism development similar to Syros. The nonimplementation of the Investment Law and the Integrated Rural Development Programmes deprive tourism development opportunities from Syros and may pave the way to other islands. As a result Syros must compete, not only the classic destinations of the Cyclades islands, but also with the new ones that grow rapidly offering similar tourist products like Syros.

\section{Lack of tourist packages}

As mentioned, the majority of foreign tourists visit destinations usually after purchasing tourist packages. Syros, due to the lack of cooperation among tour operators, cannot develop inbound tourism. Moreover, all efforts made to promote the island abroad, mainly through participation in tourism fairs, falls on deaf ears of officials.

\section{Environmental pressures from tourism development}

It is well known that tourist development can create major environmental pressures to destinations, especially if no provision is made for. The risk of creating environmental problems on the island, which will reduce tourist development in the future, is real. This threat should concern all those who are involved in the tourism development of the island.

\section{Lack of cooperation between entities}

The most important problem of Syros is the lack of cooperation between local businessmen. This is a real and ongoing problem. The image given to the visitor and to those involved in the tourist industry both in Greece and abroad is quite negative.

\section{Lack of financial resources}

The lack of financial resources, both at national and local level, makes any kind of planning for tourism development very hard to implement. Exploitation of the financial support provided through E.U. fund (like CSFs) is the only solution for developments in tourism sector. 


\section{Investors' profile}

The majority of investors are men, mainly of secondary education who are active in accommodation or catering businesses. For the two-third of them, it was the first time that they participated in a E.U. program. The main reason was the modernization and renovation of their business. Furthermore, they faced difficulties in collecting the proper documents for the various phases of the program. As a matter of fact, the majority of investors state that current procedures present few improvements if compared with previous CSF's. Nevertheless, they feel generally satisfied with the cooperation they had with the Intermediary Management Authority, which was responsible for the program.

As regards the assessment of the impact of the program on their businesses, half of them state that nothing changed. For the rest of them, positive opinions are clearly more than the negative ones. In general, it appears that income and the number of staff was increased. However, despite all the above positive effects on businesses, views on whether the 3rd CSF contributed positively to the tourism development of Syros conflict, while the average responses give moderate evaluation.

\section{S.W.O.T. ANALYSIS AFTER THE COMPLETION OF $3^{\text {RD }}$ CSF}

The S.W.O.T. analysis is based on the presentation of the situation, as it has been formed after the 3rd CSF application. This presentation aims at making known the information collected and record the possible contribution of the 3rd CSF to the Syros tourism sector. It may also assist in highlighting its strengths and improve its weaknesses of the island for further managerial use.

Table 2. SWOT Analysis

\begin{tabular}{|c|c|}
\hline Strengths & Weaknesses \\
\hline $\begin{array}{l}\text { - } \quad \text { Great historical, archaeological and cultural heritage } \\
\text { - } \quad \text { Long coastline with many beaches } \\
\text { - } \text { Good climate } \\
\text { - } \quad \text { Environment protection } \\
\text { - } \quad \text { Composcess } \\
\text { - } \text { Infrastructures } \\
\text { - } \quad \text { Young aged population } \\
\text { - } \text { Decision-making center for tourism } \\
\text { - } \quad \text { Development of domestic tourism } \\
\text { - } \quad \text { Existence of tourism infrastructures for the } \\
\quad \text { development of alternative forms of tourism }\end{array}$ & $\begin{array}{l}\text { - } \quad \text { Moderate level of services offered } \\
\text { - Inadequate maintenance of archaeological sites } \\
\text { - } \quad \text { Lack of coordinated exposure - advertising } \\
\text { - } \quad \text { Inadequate statistics records } \\
\text { - Improper utilization of infrastructure } \\
\text { - } \quad \text { Short-term tourist season } \\
\text { - } \quad \text { Reduced demand from foreigners } \\
\text { - Improper development of alternative forms of tourism } \\
\text { - } \quad \text { Lack of cooperation and organization among entities } \\
\text { - } \quad \text { "Marina Syros" project fails to integrate }\end{array}$ \\
\hline Opportunities & Threats \\
\hline 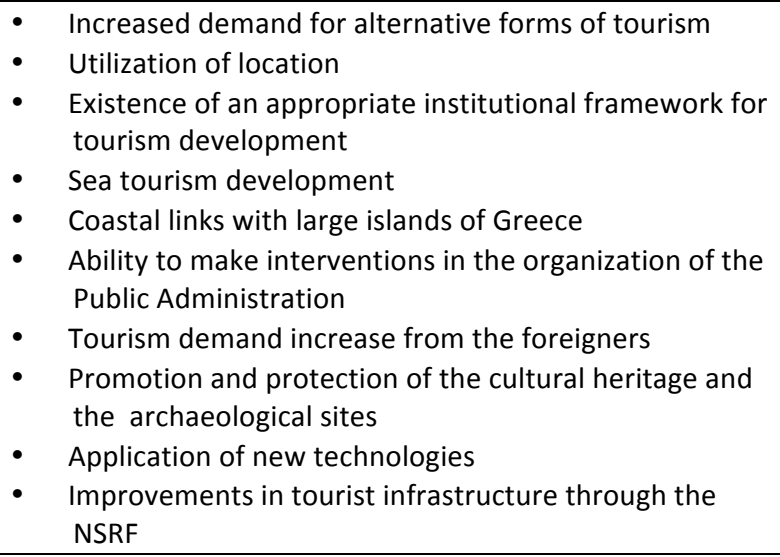 & $\begin{array}{l}\text { - Tourism development of other islands } \\
\text { - Lack of tourist packages } \\
\text { - } \quad \text { Environmental pressures from tourism development } \\
\text { - Lack of a single tourism operator } \\
\text { - Lack of financial resources } \\
\text { Increased absorption of 3rd CSF funds from the other } \\
\text { islands }\end{array}$ \\
\hline
\end{tabular}


One could easily observe that few differences exist between the two SWOT analyses tables (Table 2). Increase of entrepreneurship was added to the strengths of the island by creating new businesses, implemented via CSF facilities and by utilizing infrastructures for alternative forms of tourism, like the new berth for cruise ships. It gives Syros the great opportunity to own a cruise ship terminal.

Regarding the island's weaknesses, although the majority of businesses received funds from CSF, in order to renovate and modernize them. Nonetheless, this improvement was considered as moderate, especially in accommodation. Furthermore, another weak point is the port project abandonment (Marina Syros) which would give to the island a significant advantage, as well as, it would also create new jobs and boost income for many businessmen, either engaged in tourism or not. Given that CSF could be included in the National Strategic Reference Framework (NSRF) or even be financed from the Municipality of Syros own funds or the Region of South Aegean, it could also be referred in 'Opportunities'.

The main weak point is that the local businesses lack of central organization and planning in the tourism. Some of these entities are the region of Southern Aegean, the National Tourism Organization (Syros office), the Municipality of Syros - Ermoupolis, the Chamber of Cyclades, Cycladic Tourist Accommodation Federation, the Union of Tourist Accommodation of Syros and the Development Company of Cyclades. According to a report, this lack of understanding and strategic planning result to the existence of two different stands in Syros. Today, marina of Syros is not working due to various problems that have arisen and has turned into anchorage for fishing boats and yachts [10]. The pier created for the cruise ships has been occupied by a vessel that has been seized. In many cases, cruise ships are forced to disembark passengers with flanges, as are anchored off the coast of Syros, although they have scheduled to disembark at the port of Syros [11].

In SWOT analysis one opportunity is the existence of the National Strategic Reference Framework, which is one possible source of financing projects that were not included in the $3^{\text {rd }}$ CSF, such as the modernization of museums and archaeological sites.

In the case of threats, big absorption capacity of the $3^{\text {rd }}$ CSF from the other islands of the Cyclades has been added, which will increase their advantage towards Syros. One such project was the "Maintenance and enhancement of ancient aqueduct of Naxos and sacred water sources in Melanes" and many more, without taking into account the projects implemented in the Prefecture of Dodecanese, which belongs to the same region with the Cyclades.

\section{CONCLUSIONS AND RECOMMENDATIONS}

Nowadays, the contribution of tourism is both at national and local level. Most economic sectors are directly or indirectly affected by tourism development, while there are many other positive aspects of tourism, such as the retention of population in rural areas.

Greece is lagging behind in tourism policy making. The main reason is the way in which it is practiced. Decisions are made by the central government and their implementation is performed by local authorities. Guidelines for the formulation and application of a tourism policy were given with the implementation of E.U. funding. The same tactic applied on financial instruments, namely the CSF's, the rational application of which could increase the competitive advantage of Greece. 
The three CSFs programs that have already been applied and another one which is currently under way have improved the overall country's condition at many levels. In Syros, investments made in infrastructure through the Community frameworks are numerous and have significantly improved not only the image of the island, but also the lives of its permanent residents.

It is difficult to make a positive or negative evaluation of the Community Support Frameworks. The majority of individuals and entities involved in the research carried out in this paper admitted that the projects funded were not adequate to increase tourism development of Syros. In parallel, the existence of immeasurable elements prevents the formation of a comprehensive view. For example, the increase of a hotel's occupancy after its modernization or even the turnover increase of a tourist office after installing a computer system or office's on-line exposure.

A safe conclusion that could be extracted from the present study is that a destination, in this case Syros, cannot rely solely on the contribution of the Community Support Frameworks for its tourism development. Moreover, activities planning are necessary to exist, as well as, targets to be shared by all involved entities. One necessary stipulation is that any destination must have the necessary resources which could lead to the achievement realization of its goals. For this reason, a long-term tourism policy-making plan with clear strategies and priorities is a prerequisite.

Finally, the following recommendations are made in order the island of Syros to apply a common tourism policy:

- Development of specialized education programs on alternative tourism.

- Utilization of abandoned homes, especially those considered architectural masterpieces.

- Creation of restaurants network serving local dishes and prepared made from local products, in order to facilitate the connection between primary and tertiary sector.

- Identity creation of the high-quality local products.

- Creation of incentives in order to attract private investors to construct tourist infrastructures.

- Neorion shipyard place exploitation by converting it into a manufacturing and repairing yacht business and in conjunction with the operation of the Marina of Syros.

These indicative proposals, if applied, could give a significant boost to the island's tourism development, impacting directly or indirectly the economic and social life of its inhabitants.

\section{References}

[1] Chr. Belles, "Chios - Aegean: Demographic Realities - Tourism - Business Location”, Local Government Decentralization, AT 1, 59-66, (1999).

[2] Ministry of Tourist Development "Synthetic Text for the planning of interventions for the programming period 2007-2013 in the Tourism Sector", Athens, (2006).

[3] C. M. Hall, "Tourism and Politics - Policy, Power and Place", John Wiley \& Sons, England, (1994).

[4] H.G. Matthews, "International Tourism and Political Science Research", Annals of Tourism Research, 2 (4),195203 (1975).

[5] P. Dionysopoulou, "European Tourism Policy", Papazissis editions, Athens, (2002)

[6] O. Vitouladiti, "Manual for the Study of the Book Marketing in Travel \& Tourism", Hellenic Open University editions, Patra, (2000). 
[7] V. Stathakopoulos, "Methods of Market Research", Stamoulis editions, Athens, (2001).

[8] Community Support Frameworks 2000-2006, Greece, “Implementation Guide”, European Union, Brussels, (2000).

[9] R. Doswell, "Tourism - Role of Effective Management”, Kritiki editions, Athens, (2002).

[10] http://www.apopsy.gr/2009/t 246/eid 02.htm (Access 21/03/12)

[11] http://www.ekyklades.gr/articles/article.jsp?context=103\&categoryid=1064\&articleid=1073) (Access 22/03/12) 